\title{
Simulação de implantação de um reservatório de detenção em uma rotatória em Palmas-TO, Brasil
}

A cidade de Palmas, capital do estado do Tocantins, foi a última cidade brasileira planejada do século XX, e foi pensada para crescer de forma organizada e racional aproveitando de modo eficiente os serviços de infraestrutura urbana. Contudo, o crescimento da capital ocorreu de forma descontrolada. A urbanização desordenada da cidade deu origem a uma série de problemas de infraestrutura urbana. Palmas tem sofrido com as enchentes e, numa escala menor, com alagamentos, por conta do aumento do escoamento superficial e a cobertura de redes de drenagem deficientes. Dentre as medidas compensatórias apresentadas no Plano Municipal de Saneamento Básico do município está a implantação de reservatórios de detenção. O objetivo deste trabalho é analisar, por meio do Método de Puls, a eficiência na redução da vazão de pico à jusante decorrente da implantação de um reservatório de detenção na área de uma rotatória no Plano Diretor Sul de Palmas. O reservatório foi dimensionado na rotatória da avenida Norte-Sul-10 (NS-10) com a avenida Leste-Oeste-21 (LO-21) e a eficiência da implantação foi medida por meio do Método de Puls. O reservatório apresentou eficiência de 42,2\% para o amortecimento da vazão de pico.

Palavras-chave: Método de Puls; Reservatórios de Detenção; Amortecimento de Vazão.

\section{Simulation of deploying a detention reservoir at a traffic in Palmas- TO, Brazil}

\begin{abstract}
The city of Palmas, capital of the state of Tocantins, was the last planned Brazilian city of the twentieth century and was designed to grow in an organized and rational way, efficiently leveraging urban infrastructure services. However, the growth of the capital occurred in an uncontrolled way. The disorderly urbanization of the city gave rise to a series of problems of urban infrastructure. Palmas has suffered from flooding and, on a smaller scale, with flooding, due to increased runoff and poor drainage networks. Among the compensatory measures presented in the Municipal Basic Sanitation Plan of the municipality is the implementation of detention tanks. The objective of this work is to analyze, through the Puls Method, the efficiency in the reduction of the downstream peak flow due to the implantation of a detention reservoir in the area of a roundabout in the South Director Plan of Palmas. The reservoir was dimensioned at the North-South-10 avenue, Norte-Sul-10, with East-West-21 avenue, Leste-Oeste-21, and the efficiency of the implantation was measured using the Puls Method. The reservoir presented an efficiency of $42.2 \%$ for the peak flow damping.
\end{abstract}

Keywords: Puls Method; Detention Reservoirs; Flow Damping.

Topic: Engenharia Civil

Reviewed anonymously in the process of blind peer.
Received: 06/03/2019

Approved: 29/04/2019
Alesi Teixeira Mendes

Universidade Federal do Tocantins

http://lattes.cnpq.br/2473113080999082

alesi atm@hotmail.com

Patrick Lucas lopp

Universidade Federal do Tocantins

http://lattes.cnpq.br/8558231569044053

patrickiopp17@gmail.com
Referencing this:

MENDES, A. T.; IOPP, P. L.. Simulação de implantação de um reservatório de detenção em uma rotatória em Palmas-TO, Brasil. Technology Science, v.1, n.1, p.7-16, 2019. DOI: http://doi.org/10.6008/CBPC2674-6425.2019.001.0002 


\section{INTRODUÇÃO}

A cidade tocantinense de Palmas passou por um processo de urbanização desordenado, com uma expressiva expansão da zona urbana para regiões onde, inicialmente, não haveria crescimento da cidade. Por consequência da impermeabilização do solo, decorrente da urbanização acelerada, de obras de ocupação urbana que saturam o potencial de escoamento dos corpos hídricos urbanos, e da cobertura de redes de drenagem deficientes, Palmas tem sofrido com as enchentes e, numa escala menor, os alagamentos (PALMAS, 2014).

A rede de drenagem do município é sobrecarregada pela expansão urbana e é quase inteiramente superficial. Os terrenos impermeabilizados dos imóveis construídos lançam suas águas pluviais nas vias de circulação, esse fator somado ao aumento do número de ruas e avenidas asfaltadas contribui para o aumento do escoamento superficial, confirmando a sobrecarga da rede de drenagem (PALMAS, 2014).

Para Lopes e Souza (2012), os principais problemas enfrentados no município têm a ver com: a deficiência ou a inexistência de macro e de micro drenagem em avenidas e em algumas quadras; as dimensões inadequadas e a falta de limpeza das bocas de lobo; as condições de descargas inadequadas de águas pluviais; o lançamento de águas pluviais de imóveis edificados direto sobre vias públicas; e a falta de um plano diretor específico para a drenagem pluvial urbana.

O uso de reservatórios de detenção (RD) é umas das alternativas propostas no Plano Municipal de Saneamento Básico de Palmas para reverter a situação da drenagem urbana no município, como medida compensatória. Assim, o objetivo deste trabalho é analisar, por meio do Método de Puls, a eficiência na redução da vazão de pico à jusante decorrente da implantação de um RD na área de uma rotatória no Plano Diretor Sul de Palmas - TO. A disponibilidade e ociosidade da área das rotatórias, que, inclusive, ficam parcialmente submersas em algumas regiões durante as enxurradas, e o interesse do próprio Estado em estudar soluções compensatórias são excelentes componentes para formulação dessa pesquisa.

\section{METODOLOGIA}

\section{A Área de Estudo}

A área objeto desse estudo é a avenida Leste-Oeste-21 (LO-21) e as quadras em seu entorno. Essa avenida está localizada no Plano Diretor Sul da cidade e, de acordo com a Lei $n^{\circ} 386$, de 17 de fevereiro de 1993, que dispõe sobre a divisão da área urbana de Palmas, faz parte das áreas destinadas ao comércio e serviço vicinal. Esse trecho é confrontado ao norte pela quadra 812 Sul, ao sul pela quadra 912 Sul, pela rodovia estadual TO-050 à leste e pela avenida Norte-Sul-10 (NS-10). (Figura 1).

As quadras que cercam a LO-21 são bastante adensadas, no entanto, são pouco arborizadas e possuem deficiência em sua infraestrutura, a quadra 812 Sul, por exemplo, não é pavimentada. Essas características de uso e ocupação do solo são relevantes para a determinação de parâmetros como o Coeficiente de Runoff. A Tabela 1 apresenta os valores do coeficiente de escoamento para a área de estudo. 

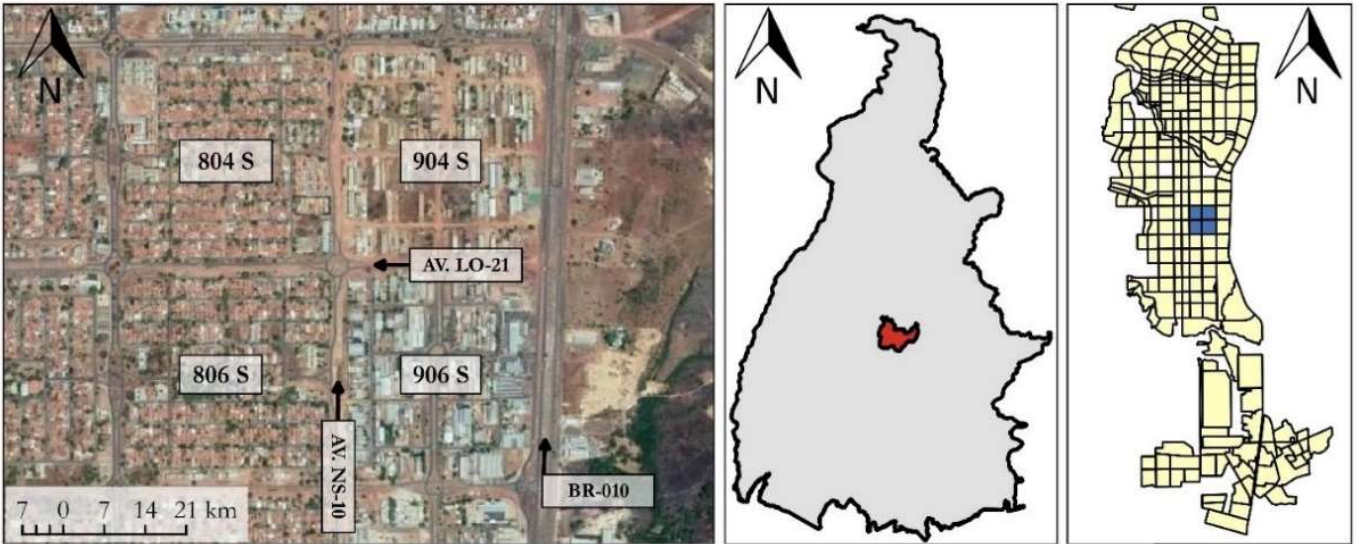

Legenda

$\square$ Estado do Tocantins

Limite Municipal de Palmas

$\square$ Limite Urbano de Palmas

Limite das Quadras Estudadas

Figura 1. Mapa da área estudada.

Tabela 1: Coeficiente de escoamento segundo uso do solo.

\begin{tabular}{lccc}
\hline \multicolumn{1}{c}{ Características da superfície } & $\begin{array}{c}\text { Área } \\
\text { (ha) }\end{array}$ & \% & $\begin{array}{c}\text { Valor } \\
\text { de C }\end{array}$ \\
\hline Superfícies impermeáveis & 10,20 & $46 \%$ & 0,80 \\
Superfícies asfaltadas & 1,66 & $\mathbf{7 \%}$ & 0,90 \\
Superfícies não revestidas & 10,36 & $47 \%$ & 0,20 \\
Total & $\mathbf{2 2 , 2 2}$ & $\mathbf{1 0 0 \%}$ & $\mathbf{0 , 5 3}$ \\
\hline
\end{tabular}

A rotatória estudada para a implantação do RD é a rotatória da avenida LO-21 com a NS-10. Por essa rotatória escoa grande parte do escoamento da LO-21 em direção ao Rio Tocantins. A Figura 2 apresenta a rotatória estudada.

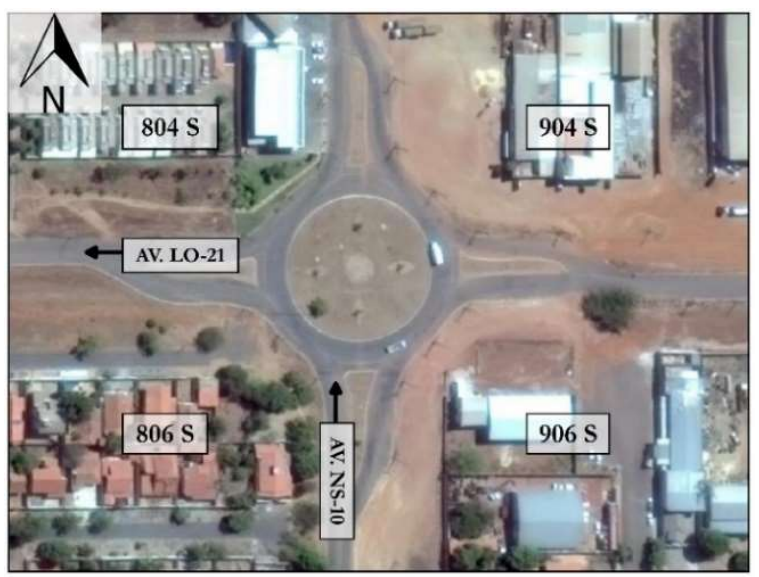

Figura 2: Rotatória da LO-21 com a NS-10.

A rotatória possui pouquíssima arborização, diâmetro de aproximadamente 70 metros, uma área de $3.893 \mathrm{~m}^{2}$ e conta com uma rede de drenagem que passa na avenida NS-10. A topografia da LO-21 apresenta declividades no sentido Leste-Oeste,-com uma amplitude de pouco mais de 10 metros. A configuração das quadras e da avenida obriga a água que escoa nessa região a passar pela Rotatória da LO-21 com a NS-10.

Não há, na Secretaria de Infraestrutura de Palmas, levantamentos topográficos das quadras nas proximidades da Avenida LO-21 impossibilitando a divisão fiel dos fluxos de escoamento nos terrenos. Deste modo, a área de contribuição foi extrapolada considerando que $1 / 6$ de cada quadra contribuía diretamente no escoamento da Avenida LO-21. A área total foi de $222.191,04 \mathrm{~m}^{2}$, pouco mais de 22 hectares. $\mathrm{O}$ fluxo do 
escoamento na Avenida LO-21 é direcionado diretamente para a rotatória onde o RD será implantado, e o comprimento do talvegue é de 596 metros.

\section{Dimensionamento do Reservatório}

De acordo com Arboit (2014), é comum que os reservatórios sejam dimensionados por procedimentos que compreendam três etapas: a determinação da vazão limite de saída do reservatório, a determinação do volume de detenção, e por fim, o dimensionamento do reservatório e das estruturas de descarga.

O RD foi dimensionado pelo Método proposto por Aron e Kibler, e apresentado por Tomaz (2002). Esse método é baseado no método racional, onde adota-se que o hidrograma da vazão afluente possui formato trapezoidal, onde o pico da vazão efluente situa-se no trecho de recessão do trapézio e a vazão de saída possui formato triangular. O cálculo do volume de detenção é obtido por meio da Equação 1:

$$
V d=Q a x t d-Q p \frac{(t d+t c)}{2}
$$

Onde td é a duração da chuva ( $\min$ ); tc o tempo de concentração $(\min )$ da bacia no ponto em questão; Vd é o volume de detenção $\left(\mathrm{m}^{3}\right)$; Qe é a vazão efluente $\left(\mathrm{m}^{3} / \mathrm{s}\right)$; e Qa é a vazão afluente $\left(\mathrm{m}^{3} / \mathrm{s}\right)$. A vazão afluente é calculada pela equação a seguir:

$$
Q a=\frac{\operatorname{CxI} x A}{1000}
$$

Onde $\mathrm{C}$ é o coeficiente de escoamento e $\mathrm{A}$ é a área da bacia (ha). A intensidade média da chuva (I em L/s.ha) é obtida por meio da Equação 3, a seguir:

$$
I=\frac{4855,3 \times \operatorname{Tr}^{0,181}}{(t+15)^{0,89}}
$$

O valor do tempo de retorno ( $\mathrm{Tr}$ ) adotado nesse projeto foi de 10 anos, a fim de garantir a segurança de implantação do RD e também evitar a ociosidade do empreendimento nos períodos de recessão. O volume de detenção é obtido por meio de tentativas, variando o tempo de duração da chuva (t).

Para dimensionar o volume de detenção do reservatório é preciso conhecer qual a sua vazão máxima efluente. Essa vazão é o volume que o dispositivo consegue escoar para a rede de microdrenagem. $O$ volume detido pelo RD será escoado na rede de drenagem pré-existente na NS-10, por meio de uma tubulação de concreto. Como a condução do escoamento para a rede de microdrenagem será por tubulações o cálculo da vazão efluente atende a equação de Manning.

$$
Q e=\frac{\left(A_{c} \times R^{\frac{2}{3}} \times I^{\frac{1}{2}}\right)}{n}
$$

Onde Ac é a área da seção transversal molhada da manilha $\left(\mathrm{m}^{2}\right)$; R o raio hidráulico $(\mathrm{m})$; I a declividade $(\mathrm{m} / \mathrm{m})$; e n o coeficiente de rugosidade de Manning. O coeficiente de rugosidade de Manning é um parâmetro diretamente associado a forma como os fluidos escoam sobre uma superfície. 
A tubulação escolhida para conduzir o efluente para a rede de drenagem foi de concreto com 1,0 m de diâmetro, admitindo-o em bom estado de conservação ( $\eta=0,013)$. Os parâmetros adotados para a determinação da vazão efluente são apresentados na Tabela 1.

Tabela 2: Características do tubo de saída.

\begin{tabular}{lc}
\hline Parâmetro & Valor \\
\hline Tubo adotado $(\mathrm{m})$ & 1,00 \\
Ac - Área da seção molhada da manilha $\left(\mathrm{m}^{2}\right)$ & 0,67 \\
$\mathrm{R}$ - Raio hidráulico $(\mathrm{m})$ & 0,30 \\
$\mathrm{y} / \mathrm{d}$ & 0,8 \\
$\mathrm{I}$ - Declividade $(\mathrm{m} / \mathrm{m})$ & 0,01 \\
$\eta$ - Coeficiente de rugosidade de Manning & 0,013 \\
\hline
\end{tabular}

O tempo de concentração (tc) foi obtido pelo método desenvolvido por Kirpich, por meio da equação a seguir:

$$
T c=57 x\left(\frac{L^{3}}{H}\right)^{0,385}
$$

Onde tc é o tempo de concentração ( $\mathrm{min})$; L é o comprimento do talvegue $(\mathrm{km})$; e H é a amplitude da bacia (m). O valor de tc equivale a 12,92 minutos e, por questões de praticidade, esse valor foi adotado com sendo 13 minutos. O tempo de duração da precipitação máxima é estimado por tentativas e variou de 15 até 180 minutos, sendo que o tempo de duração que gerou o maior volume de reservação foi de 30 minutos.

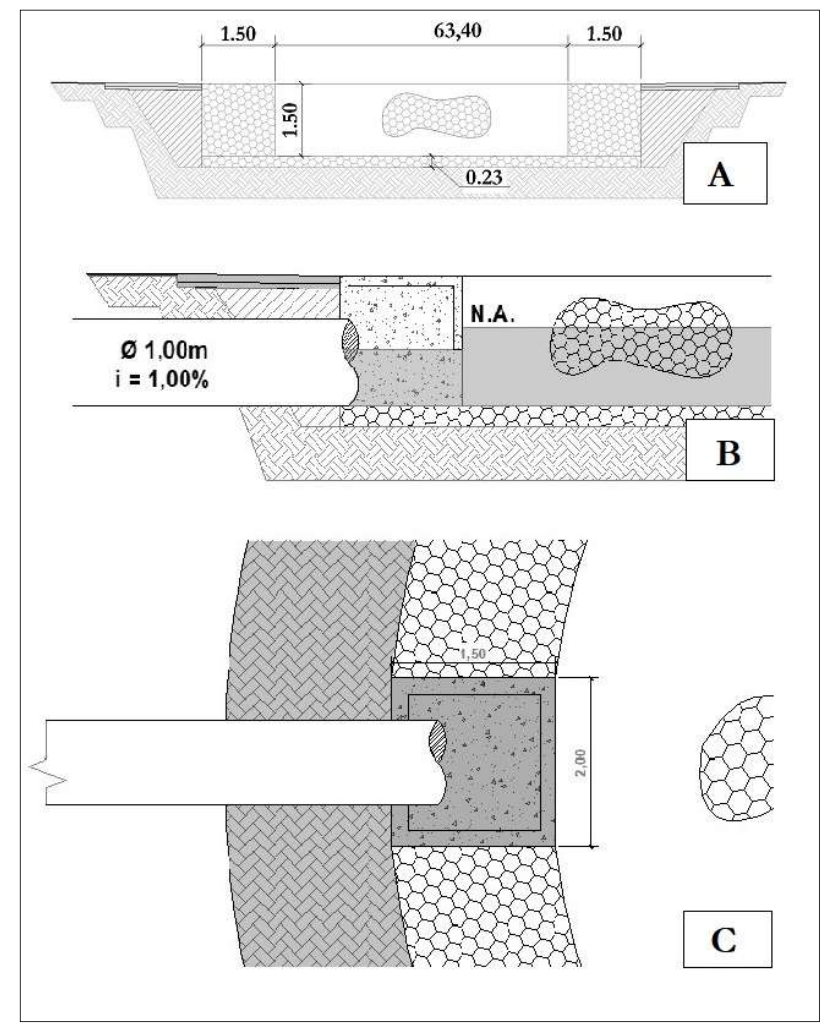

Figura 3: Detalhes esquemáticos do RD. Legenda: (A) Corte do reservatório; (B) Vista lateral com detalhe na tubulação de descarga; (C) Vista superior com detalhe na tubulação de descarga.

A geometria escolhida para o reservatório é circular a fim de melhor aproveitar a área disponível da rotatória. A rotatória possui uma área total de pouco mais de $3.893 \mathrm{~m}^{2}$, no entanto, nem toda área foi 
escolhida para implantação, foi determinado um afastamento interno de 2,0 metros do limite da rotatória para a área que denominaremos aqui como operativa. Para otimização do volume de detenção, o reservatório será executado em gabião, assim dispensando o uso de taludes laterais acentuados.

De acordo com Chuquimuni (2005), a utilização de gabiões possui uma série de vantagens. No que diz respeito aos aspectos estruturais, os gabiões são elementos bastante flexíveis e permitem que a estrutura se acomode aos recalques diferenciais sem que ocasione danos sérios a estrutura do muro. Além disso, são estruturas permeáveis e drenantes, favorecendo a minimização dos empuxos hidrostáticos sobre o muro e a malha de arame galvanizado garante a geometria do sólido, formando um conjunto capaz de absorver os empuxos horizontais e transmiti-los ao solo. A profundidade adotada foi de 1,5 metros. Descontando a largura dos gabiões, a área final de reserva foi de 3157,90 $\mathrm{m}^{2}$. Considerando a altura adotada, o RD possui uma capacidade de reservar $4736,85 \mathrm{~m}^{3}$.

\section{A Análise de Eficiência}

A eficiência do RD foi atestada pelos resultados obtidos na comparação dos escoamentos pelos hidrogramas de pré e pós-implantação. O hidrograma muda com a implantação do dispositivo de amortecimento, pois retarda a vazão de pico e, assim, os seus valores sofrem uma atenuação decorrente da regulagem dos dispositivos de extravasão.

Para análise de eficiência, antes de elaborar os hidrogramas afluente e efluente para análise de eficiência, foi necessário desenvolver outras análises preliminares. A primeira dessas análises foi a do hietograma de projeto.

O hietograma foi desenvolvido levando em consideração a chuva crítica para Palmas, por meio da equação de chuvas intensas de Palmas para precipitações com duração determinada. Foi adotada a equação apresentada pelo PMSB de Palmas, desenvolvida nos estudos do Plano Diretor de Drenagem Pluvial, com coeficiente de correlação em 99,97\% (PALMAS, 2014):

$$
i=\frac{749,97 \times T^{0,104}}{(t+9)^{0,702}}
$$

O método utilizado foi o dos Blocos Alternados, que deriva das relações de chuvas intensas e que atribui em cada intensidade do hietograma um mesmo período de retorno. Os valores dos parâmetros para a determinação do hietograma são apresentados na Tabela 3.

Tabela 3: Valores obtidos para composição do hietograma.

\begin{tabular}{ccccc}
\hline Duração da chuva (min) & $\begin{array}{c}\text { Chuva } \\
\text { crítica } \\
(\mathbf{m m} / \mathbf{h})\end{array}$ & Precip. $(\mathbf{m m})$ & $\begin{array}{c}\text { Precip. excedente } \\
\text { (mm) }\end{array}$ & $\begin{array}{c}\text { Precip. efetiva } \\
\text { (mm) }\end{array}$ \\
\hline $\mathbf{0}$ & 203,78 & 0,00 & 0,00 & 0,00 \\
$\mathbf{1 5}$ & 102,36 & 2,21 & 0,11 & 2,10 \\
$\mathbf{3 0}$ & 72,80 & 2,60 & 0,18 & 2,42 \\
$\mathbf{4 5}$ & 57,93 & 3,22 & 0,84 & 2,38 \\
$\mathbf{6 0}$ & 48,77 & 4,33 & 2,00 & 2,33 \\
$\mathbf{7 5}$ & 42,48 & 7,05 & 4,50 & 2,55 \\
$\mathbf{9 0}$ & 37,85 & 25,59 & 21,34 & 4,25 \\
$\mathbf{1 0 5}$ & 34,28 & 10,81 & 9,93 & 0,88 \\
$\mathbf{1 2 0}$ & 31,43 & 5,32 & 4,98 & 0,34 \\
\hline
\end{tabular}




\begin{tabular}{lllll}
135 & 29,10 & 3,68 & 3,47 & 0,21 \\
150 & 27,14 & 2,87 & 2,72 & 0,15 \\
165 & 25,48 & 2,39 & 2,27 & 0,12 \\
180 & 24,04 & 2,06 & 1,96 & 0,10 \\
\hline
\end{tabular}

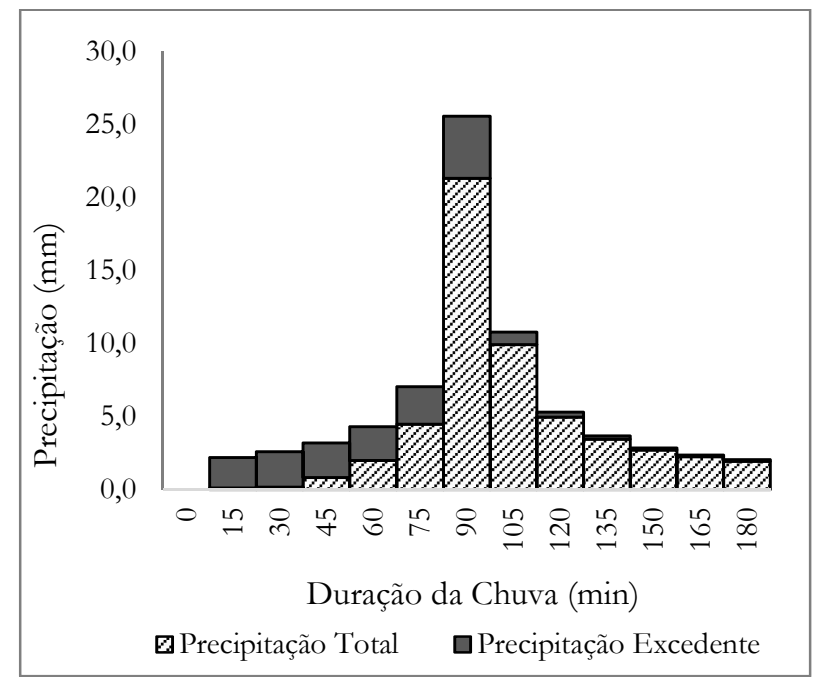

Figura 4: Hietograma de projeto.

O comportamento do escoamento foi observado através do Método Puls que, conforme Tucci (1998, p. 136), "é um dos métodos mais conhecidos para a simulação do escoamento em reservatório". O método se baseia na equação da continuidade concentrada, sem contribuição lateral e estabelecendo uma relação entre a reservação e a vazão do reservatório, considerando a linha de água horizontal.

Tucci e Genz (1995) aplicam o método de Puls em um estudo sobre a utilização de bacias de detenção para controle do impacto da urbanização. Tomaz (2002) utiliza o método de Puls modificado no dimensionamento do RD do Pacaembu em São Paulo, onde a estrutura extravasor é uma

combinação de vertedor e orifício. Canholi (2005), em seu estudo sobre os RD e inundações urbanas, utiliza o método com diferentes estruturas de saída. Hernandez (2007), em seu trabalho sobre propagação de enchentes em reservatórios, realiza uma análise comparativa entre o método de Puls e o método direto. O cálculo é realizado por meio da Equação 7.

$$
Q_{t+1}+\frac{2 S_{t+1}}{\Delta t}=I_{t}+I_{t+1}-Q_{t}+\frac{2 S_{t}}{\Delta t}
$$

Onde l e $\mathrm{I}_{\mathrm{t}+1}$ são as vazões de entrada no RD no tempo t e $t+1$; $Q$ e $\mathrm{Q}_{\mathrm{t}+1}$ são as vazões de saída do RD no tempo $t$ e $t+1$; e $S$ e $S_{t+1} \circ$ armazenamento também nos períodos de tempo $t$ e $t+1$. Essa equação faz relação com outras duas equações que representam o armazenamento e a vazão do reservatório.

$$
\begin{gathered}
Q=f(S) \\
Q=f 1\left(Q+\frac{2 S}{\Delta t}\right)
\end{gathered}
$$

\section{RESULTADOS E DISCUSSÃO}

A avenida NS-10 possui uma rede de drenagem, que não está cadastrada no sistema da Secretaria de Infraestrutura, contudo dispõe dos registros do trecho subsequente. Esse trecho possui um posto de visita (PV) com cota do terreno em 281,813 m e conta de fundo em 276,724 m. Além disso, a tubulação dessa rede 
é dupla de diâmetros de 1,50 m com inclinação de 0,5\%. A distância do centro de uma das rotatórias ao centro da outra é de $700 \mathrm{~m}$. A cota de terreno do RD é $281,915 \mathrm{~m}$ e a cota de fundo $280,415 \mathrm{~m}$.

Tabela 4: Volume de detenção pelo Método de Aron e Kibler.

\begin{tabular}{|c|c|c|c|c|c|c|c|}
\hline $\begin{array}{l}\text { Tc - Tempo de } \\
\text { concentração } \\
\text { (min) }\end{array}$ & $\begin{array}{c}\text { Qe - } \\
\text { Efluente } \\
\left(\mathrm{m}^{3} / \mathrm{s}\right)\end{array}$ & $\begin{array}{c}\mathrm{Tr}-\text { Tempo de } \\
\text { retorno } \\
\text { (anos) }\end{array}$ & $\begin{array}{l}\mathrm{t} \text { - Duração da } \\
\text { chuva } \\
\text { (min) }\end{array}$ & $\begin{array}{c}\text { i - Intensidade de } \\
\text { chuva } \\
\text { (L/s.ha) }\end{array}$ & $\begin{array}{l}\text { A - } \\
\text { Área } \\
\text { (ha) }\end{array}$ & $\begin{array}{c}\text { Qa - } \\
\text { Afluente } \\
\left(\mathrm{m}^{3} / \mathrm{s}\right)\end{array}$ & $\begin{array}{c}\text { Vd - Volume de } \\
\text { detenção } \\
\left(\mathrm{m}^{3}\right)\end{array}$ \\
\hline 13 & 2,34 & 10 & 15 & 421,31 & 22,22 & 4,94 & 2477,59 \\
\hline 13 & 2,34 & 10 & 30 & 293,69 & 22,22 & 3,44 & 3175,35 \\
\hline 13 & 2,34 & 10 & 45 & 227,35 & 22,22 & 2,67 & 3119,57 \\
\hline 13 & 2,34 & 10 & 60 & 186,40 & 22,22 & 2,19 & 2735,33 \\
\hline 13 & 2,34 & 10 & 75 & 158,48 & 22,22 & 1,86 & 2174,32 \\
\hline 13 & 2,34 & 10 & 90 & 138,16 & 22,22 & 1,62 & 1505,43 \\
\hline 13 & 2,34 & 10 & 105 & 122,68 & 22,22 & 1,44 & 764,91 \\
\hline 13 & 2,34 & 10 & 120 & 110,47 & 22,22 & 1,30 & $-26,11$ \\
\hline 13 & 2,34 & 10 & 135 & 100,58 & 22,22 & 1,18 & $-854,38$ \\
\hline 13 & 2,34 & 10 & 150 & 92,40 & 22,22 & 1,08 & $-1711,12$ \\
\hline 13 & 2,34 & 10 & 165 & 85,52 & 22,22 & 1,00 & $-2590,23$ \\
\hline 13 & 2,34 & 10 & 180 & 79,64 & 22,22 & 0,93 & $-3487,34$ \\
\hline
\end{tabular}

O PV está a 30 metros de distância do RD e, admitindo que sua tubulação respeita as mesmas configurações da rede registrada da NS-10, não há impedimento para a utilização da inclinação (1\%) e do diâmetro $(\varnothing 1,00 \mathrm{~m})$ escolhidos para a vazão efluente do reservatório.

Em síntese o volume de detenção é a diferença entre o volume afluente e o volume efluente que, por sua vez, são produto das vazões afluentes e efluentes pelo tempo de duração da chuva. Assim, os valores obtidos para os volumes de detenção são apresentados na Tabela 4.

O valor adotado para o dimensionamento do RD foi o que apresenta a condição de maior volume de reservação, um total de $3175,35 \mathrm{~m}^{3}$. A partir dos valores de escoamento obtidos foi possível determinar o escoamento superficial da LO-21. Esse escoamento é justamente o hidrograma afluente que representa a condição da sub-bacia sem a implantação do RD.

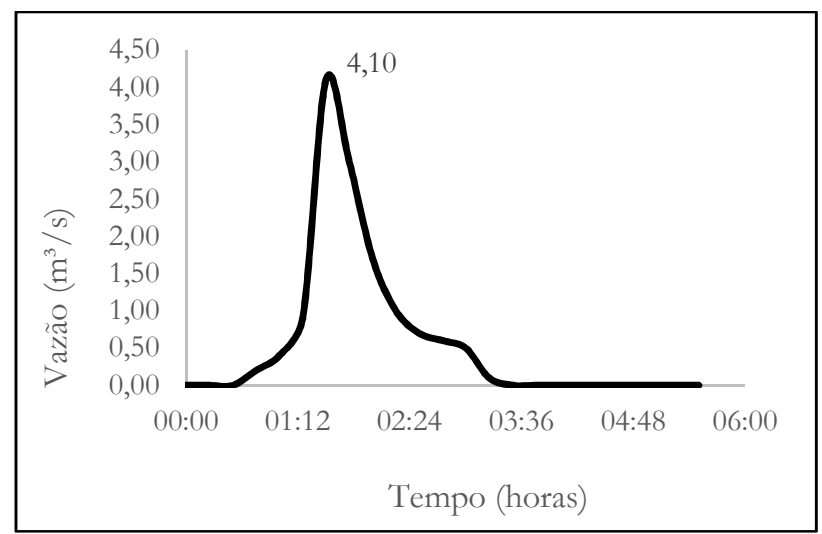

Gráfico 1: Hidrograma afluente.

Como o cálculo do hietograma foi desenvolvido para uma chuva crítica de Palmas o valor do escoamento crítico foi de $4,1 \mathrm{~m}^{3} / \mathrm{s}$ para um tempo de retorno de 10 anos. $O$ reservatório foi dimensionado considerando a vazão afluente de $3,44 \mathrm{~m}^{3} / \mathrm{s}$, logo, nessa condição, o RD estaria utilizando a sua borda-livre. O Método de Puls relaciona o volume do reservatório a sua vazão de descarga. Como a descarga do RD será por meio de um tubo seu valor é obtido por meio da equação de Manning (Equação 4).

Tabela 5: Vazões afluentes e efluentes. 


\begin{tabular}{|c|c|c|c|}
\hline$\Delta \mathrm{t}$ & qa - vazão afluente $\left(\mathrm{m}^{3} / \mathrm{s}\right)$ & $\mathrm{v}$ - volume $\left(\mathrm{m}^{3}\right)$ & qe - vazão efluente $\left(\mathrm{m}^{3} / \mathrm{s}\right)$ \\
\hline 00:00 & 0,00 & 0,00 & 0,00 \\
\hline $00: 15$ & 0,00 & 0,00 & 0,00 \\
\hline $00: 30$ & 0,00 & 0,00 & 0,00 \\
\hline $00: 45$ & 0,20 & 84,21 & 0,01 \\
\hline 01:00 & 0,40 & 330,48 & 0,06 \\
\hline 01:15 & 0,90 & 770,53 & 0,32 \\
\hline 01:30 & 4,10 & 2153,69 & 1,93 \\
\hline 01:45 & 3,00 & 4281,21 & 2,36 \\
\hline 02:00 & 1,70 & 4578,96 & 2,36 \\
\hline 02:15 & 1,00 & 4727,95 & 2,36 \\
\hline 02:30 & 0,70 & 4423,5 & 2,37 \\
\hline 02:45 & 0,60 & 3942,9 & 2,37 \\
\hline 03:00 & 0,50 & 3369,9 & 2,37 \\
\hline 03:15 & 0,10 & 2571,4 & 2,37 \\
\hline 03:30 & 0,00 & 1891,9 & 1,61 \\
\hline 03:45 & 0,00 & 1431,2 & 1,01 \\
\hline 04:00 & 0,00 & 1129,56 & 0,67 \\
\hline 04:15 & 0,00 & 924,58 & 0,45 \\
\hline 04:30 & 0,00 & 774,82 & 0,33 \\
\hline $04: 45$ & 0,00 & 667,39 & 0,24 \\
\hline 05:00 & 0,00 & 583,84 & 0,19 \\
\hline 05:15 & 0,00 & 514,08 & 0,15 \\
\hline $05: 30$ & 0,00 & 0,00 & 0,00 \\
\hline $05: 45$ & 0,00 & 0,00 & 0,00 \\
\hline
\end{tabular}

O hidrograma efluente é resultado da relação entre as curvas das funções das Equações 24 e 25 . A função que determina o escoamento efluente considera que no decorrer da precipitação haverá uma vazão $\mathrm{Q}$ somada a um volume de reservação $\mathrm{S}$, que é multiplicado por dois e dividido pelo intervalo de tempo $\Delta t$ de projeto. A partir de um valor de reserva inicial se obtém pela relação das curvas acima o valor do volume e da vazão efluente para casa período de tempo. 0 volume inicial adotado foi de 0 (zero) assumindo que o reservatório está vazio antes do início da precipitação. Com os valores das vazões afluentes e efluentes no tempo obtemos o hidrograma que representa o comportamento do escoamento na sub-bacia após a implantação do RD (Tabela 5).

O RD atenua o pico de vazão crítico e distribui o escoamento mais uniformemente no decorrer do tempo. A parte mais alta do hidrograma efluente está constante em $2,37 \mathrm{~m}^{3} / \mathrm{s}$ por conta da característica do dispositivo extravasor (Gráfico 2). Se, ao invés de um tubo, o dispositivo fosse um vertedouro, o crescimento do hidrograma acompanharia o aumento do volume. Com a descarga por tubulações quando se atinge determinado volume a vazão efluente se mantém constante. Com base no método utilizado, o RD proposto nesse trabalho apresentou uma eficiência de $42,2 \%$ para o amortecimento da vazão de pico à jusante.

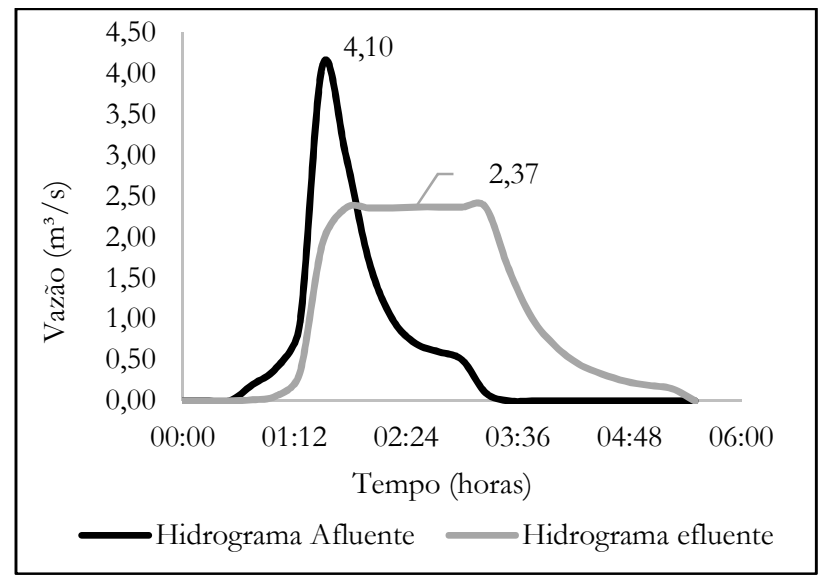

Gráfico 2: Hidrogramas afluente e efluente. 


\section{CONCLUSÃO}

O reservatório dimensionado possui uma capacidade de reservar $4736,85 \mathrm{~m}^{3}$ e eficiência de $42,2 \%$ para o amortecimento da vazão de pico. Essa proposta de implantação se restringiu ao problema da Avenida LO-21, no entanto a gestão da drenagem urbana deve buscar integrar os sistemas de todo município, de modo que a ideia ou o conceito dessa implantação pode ser aplicado em outros pontos críticos de Palmas.

O cenário ideal para a infraestrutura de drenagem urbana de Palmas é que, conforme indica Tucci (2000), se busque desenvolver um Plano Diretor de Drenagem Urbana que preze preservar as áreas de infiltração naturais ou artificiais; regular os volumes de escoamento; e repensar o espaço urbano através de projetos paisagísticos adequados. Contudo, a realidade atual ainda é marcada pelo uso, em maior escala, de medidas com caráter corretivo e paliativo. Dessa forma, a implantação de RD, na situação estudada, é uma alternativa eficiente para reduzir o escoamento superficial a jusante, evitando problemas como enchentes e inundações nas avenidas.

\section{REFERÊNCIAS}

ARBOIT, N. K. S.. Proposta de implementação de microreservatório de detenção em lotes na cidade de Frederico Westphalen. Monografia (Graduação em Engenharia Ambiental e Sanitária) - Universidade Federal de Santa Maria, Frederico Westphalen, 2014.

CANHOLI, A. P.. Drenagem urbana e controle de enchentes. São Paulo: Oficina de Textos, 2005.

CHUQUIMUNI, R. A. A.. Análise Numérica do Alteamento de Barragens de Terra. Dissertação (Mestrado em Engenharia Civil) - Pontífice Universidade Católica do Rio de Janeiro, Rio de Janeiro, 2005.

HERNANDEZ, V.. Propagação de Enchentes em Reservatórios - Método Direto. RBRH, v.12, n.2, p.115-122, 2007.

LOPES, R. C.; SOUZA, L. B.. A questão das inundações em Palmas (TO), segundo a percepção de moradores e usuários: contribuição ao processo preventivo por meio da educação ambiental. Interface (Porto Nacional), n.5, p.35-48, 2012.
PALMAS. Plano Municipal de Saneamento Básico de Palmas - TO. Anexo III ao Decreto no 700, de 15 de janeiro de 2014. v. III: Drenagem Urbana. Palmas, 2014.

TOMAZ, P.. Cálculos hidrológicos e hidráulicos para obras municipais. São Paulo: Navegar, 2002.

TUCCI, C. E. M.. A necessidade do planejamento da drenagem urbana. In: TUCCI, C. E. M.; MARQUES, D. M. L. M.. Avaliação e controle da drenagem urbana. Porto Alegre: UFRGS, 2000. p.499-501.

TUCCI, C. E. M.; GENZ, F.. Controle do impacto da urbanização. In: TUCCI, C. E. M.; PORTO, R. L. L.; BARROS, M. T.. Drenagem Urbana. Porto Alegre: ABRH, 1995.

TUCCI, C. E. M.. Modelos hidrológicos. Porto Alegre: UFRGS, 1998.

A CBPC - Companhia Brasileira de Produção Científica (CNPJ: 11.221.422/0001-03) detém os direitos materiais desta publicação. Os direitos referem-se à publicação do trabalho em qualquer parte do mundo, incluindo os direitos às renovações, expansões e disseminações da contribuição, bem como outros direitos subsidiários. Todos os trabalhos publicados eletronicamente poderão posteriormente ser publicados em coletâneas impressas sob coordenação da Sapientiae Publishing, da Companhia Brasileira de Produção Científica e seus parceiros autorizados. Os (as) autores (as) preservam os direitos autorais, mas não têm permissão para a publicação da contribuição em outro meio, impresso ou digital, em português ou em tradução. 